\title{
Asthma, enuresis, and chronic illness: long term impact on height
}

Epidemiology and Biostatistics, Institute of Child Health Guilford St, London WC1N 1EH C Power

School of Public Health and

Community Medicine, Hebrew University, Jerusalem

O Manor

Correspondence and reprint requests to: Dr Power.

Accepted 12 July 1995

\author{
Chris Power, Orly Manor
}

\begin{abstract}
Objective-To determine whether common conditions in early childhood, such as asthma and psychosocial illness (mainly enuresis), affect height during later childhood and in adult life.

Design-Longitudinal follow up of subjects in the 1958 British Birth Cohort Study. Data from the birth survey and ages 7, 11, 16 , and 23 were used.

Subjects-12 537 subjects remaining in the study at age 23 , representing $76 \%$ of the target population, cohort members still alive and resident in Britain.

Results-Heights of children with allergic, acute or psychosomatic illness, or asthma/wheezy bronchitis did not differ by age 7 from those of children without such illnesses. When asthma was graded by severity, there was a trend (not significant) for the severe group to be shorter at ages 16 and 23. Although children with a chronic illness by age 7 were on average almost 0.5 cm shorter than children without such illnesses, this difference was reduced by half and was not significant after adjusting for maternal height, birth weight, parity, and social class at birth. However, a marked and long lasting effect was found for children with psychosocial illness who at age 7 were significantly shorter, by a mean of $0.77 \mathrm{~cm}$. Within this group, enuretic children with a problem at age 11 were more than $1 \mathrm{~cm}$ shorter in adulthood, even allowing for other height related factors.

Conclusions-Common childhood illnesses do not appear to affect height, either in the short or in the long term, although exceptions include chronic illness and enuresis. The value of height as an indicator of child health status in an industrialised country such as Britain requires further reassessment.

(Arch Dis Child 1995; 73: 29.8-304)
\end{abstract}

Keywords: height, childhood illness, asthma, enuresis, longitudinal study.

Many factors influencing height have been identified, including birth weight, parental height, birth order, number of younger siblings, overcrowding, maternal age, social class, and region. ${ }^{1-6}$ Effects of childhood illness on height have not been determined, except for some uncommon conditions such as thyroid disorders, sickle cell anaemia, and congenital heart disease. ${ }^{7}$ Asthma may retard growth in childhood, ${ }^{8-10}$ although few studies have investigated adult height. ${ }^{11} 12$ An adverse effect of psychosocial stress is implicated by studies showing stunting of children with certain emotional disorders. ${ }^{13}$ The possibility remains that common childhood conditions might affect childhood growth and adult height.

There is an additional reason to consider the role of childhood illness, apart from possible aetiological effects on growth and adult stature. With the decline in childhood mortality, greater emphasis is given to morbidity in child health monitoring. Recent overviews illustrate the need for indices of child health. ${ }^{1415}$ Anthropmetric measures, particularly height, are often cited as proxies for child health, but this has not been evaluated.

This paper uses longitudinal data from the large, nationally representative 1958 British birth cohort to investigate whether childhood illness affects growth in the short term and over a longer period in the attainment of adult stature.

\section{Methods}

SAMPLE

The 1958 British Birth Cohort Study includes all children born in Scotland, Wales, and England between the 3rd and the 9th of March $1958 .{ }^{16}$ From a target population of 17733 births, information was obtained on $98 \%$. Major follow up of surviving children was conducted at ages $7,11,16,23$, and latterly at 33 years of age. ${ }^{17}$ Immigrants to Britain born during the same week in 1958 were incorporated into the survey at ages 7,11 , and 16 . Sample attrition has occurred, but despite this the representativeness of the study has been maintained, in general, through to age 23 , when 12537 subjects ( $76 \%$ of the target population) provided information. 618 Some biases have occurred, notably for certain disadvantaged groups: for example those with psychosocial illness and some chronic conditions at age 7 were underrepresented in the sample at age $23 .{ }^{19}$

Information at age 23 was obtained through personal interview with the study subject. Previous sweeps collected data from several sources, including parents and schools (teachers and doctors) as well as from the individuals.

\section{MEASURES}

Heights were measured in a school medical examination at 7,11 , and 16 years. The month of measurement was also recorded. Measurements were made according to a detailed protocol in order to minimise measurement error. At age 23 heights were self reported. These reports are in agreement with measured heights in a national sample of British adults 
surveyed in $1980 . .^{20}$ Data were checked to detect coding errors. ${ }^{21}$

Information on childhood illnesses was recorded in school medical examinations and parental interviews at ages 7,11 , and 16 . The following illness categories, defined previously, ${ }^{19}$ summarise the medical information obtained at the seven year sweep:

(1) Acute: includes, for example, tonsillitis, otitis media, tuberculosis, glandular fever, pneumonia, and urinary infection (common childhood infectious diseases such as measles, chicken pox, and mumps were not included).

(2) Asthma or wheezy bronchitis.

(3) Allergies: eczema and hayfever.

(4) Chronic conditions: disaggregated into three subgroups, namely physical or mental handicap, sensory impairment, and chronic medical conditions (for example, disorders of the cardiovascular or urogenital systems).

(5) Psychosocial: mainly enuresis and/or soiling, but also a small proportion of children assessed as maladjusted by the school doctor. (6) Psychosomatic: abdominal pain, vomiting or bilious attack, frequent headaches.

(7) No recorded illness or injury in categories listed above.

For more detailed analyses of psychosocial problems, information on enuresis obtained at ages 7 and 11 was used to identify those with (1) enuresis by age 7 (that is, wetting by day after age 3 or at night after age 5) but not thereafter; (2) enuresis by age 7 and at age 11 (nocturnal enuresis in the preceding month), or age 11 only; and (3) no enuresis.

Information obtained at subsequent follow up was also used for asthma or wheezy bronchitis (AWB). Six categories, similar to those used by Anderson et al, ${ }^{22}$ were derived as a proxy for disease duration: (1) AWB before age 7 but not thereafter; (2) AWB recorded at each of the 7, 11, and 16 year sweeps; (3) AWB recorded at either 11 or 16 years; (4) AWB at ages 11 and 16 but not before age 7; (5) AWB before age 7 and recorded at either 11 or 16 years; (6) no report of AWB. Reports of frequency of attacks in the preceding 12 months were used to further classify AWB at ages 11 and 16: attacks occurring once a month or more were classified as 'severe'.
Other variables, obtained from the original perinatal mortality survey, ${ }^{16}$ are as follows:

Birth weight was measured in ounces;

Maternal height was either self reported or recorded from measurements in the case sheets;

Parity was grouped into (1) no previous pregnancies of 28 weeks or more, and (2) one or more pregnancies;

Social class at birth was based on father's occupation (coded according to the Registrar General's 1950 classification) and grouped into non-manual and manual classes (children with no male head of household were included in the latter).

\section{DATA ANALYSIS}

As in earlier work on this cohort, ${ }^{1}$ analyses were confined to singletons, twins having a different growth pattern. Mean heights are presented for each morbidity group and sex separately. However, when relationships between height and morbidity were assessed to establish whether they differed for males and females, in general the interactions were not significant. Thus both sexes are combined, with allowance made for sex in the model. Date of height measurement was accounted for by fitting a linear regression in the analyses.

Analysis of covariance (ANCOVA) was used to examine the association between childhood illness and height. Separate analyses were performed for each age. Unadjusted heights were derived with allowance only for sex and the measurement date for height. ANCOVAs were repeated with additional adjustment for major factors known to be related to height, namely maternal height, birth weight, parity, and social class at birth. Adjusted heights given in the results allow for these factors unless otherwise stated. Adjustment for fathers' height was undertaken but because no additional effect was found, it is omitted from the results.

\section{Results}

Table 1 shows mean height at different ages according to childhood morbidity at age 7

Table 1 Mean height (metres) and childhood illness at age 7

\begin{tabular}{|c|c|c|c|c|c|c|c|c|c|c|c|c|}
\hline \multirow[b]{3}{*}{ Illness at age $7 \star$} & \multicolumn{12}{|c|}{ Age at follow up } \\
\hline & \multicolumn{3}{|c|}{7 Years } & \multicolumn{3}{|c|}{11 Years } & \multicolumn{3}{|c|}{16 Years } & \multicolumn{3}{|c|}{23 Years } \\
\hline & Mean & $S D$ & No & Mean & $S D$ & No & Mean & $S D$ & No & Mean & $S D$ & No \\
\hline $\begin{array}{l}\text { Male } \\
\text { Acute } \\
\text { Asthma/wheezy bronchitis } \\
\text { Allergies } \\
\text { Chronic } \\
\text { Psychosocial } \\
\text { Psychosomatic } \\
\text { None }\end{array}$ & $\begin{array}{l}1 \cdot 230 \\
1.227 \\
1.235 \\
1.222 \\
1.220 \\
1.230 \\
1.228\end{array}$ & $\begin{array}{l}0.059 \\
0.059 \\
0.056 \\
0.063 \\
0.060 \\
0.060 \\
0.057\end{array}$ & $\begin{array}{r}3152 \\
1409 \\
862 \\
1075 \\
1072 \\
1950 \\
1327\end{array}$ & $\begin{array}{l}1.443 \\
1.441 \\
1.447 \\
1.434 \\
1.430 \\
1.443 \\
1.439\end{array}$ & $\begin{array}{l}0.069 \\
0.070 \\
0.066 \\
0.075 \\
0.070 \\
0.071 \\
0.069\end{array}$ & $\begin{array}{r}2641 \\
1176 \\
749 \\
881 \\
869 \\
1654 \\
1110\end{array}$ & $\begin{array}{l}1.706 \\
1.702 \\
1.713 \\
1.696 \\
1.694 \\
1.707 \\
1.702\end{array}$ & $\begin{array}{l}0.079 \\
0.081 \\
0.076 \\
0.090 \\
0.084 \\
0.082 \\
0.077\end{array}$ & $\begin{array}{r}2228 \\
959 \\
615 \\
731 \\
743 \\
1352 \\
953\end{array}$ & $\begin{array}{l}1.776 \\
1.774 \\
1.777 \\
1.768 \\
1.771 \\
1.777 \\
1.776\end{array}$ & $\begin{array}{l}0.069 \\
0.071 \\
0.067 \\
0.074 \\
0.073 \\
0.070 \\
0.069\end{array}$ & $\begin{array}{r}2418 \\
1076 \\
679 \\
799 \\
784 \\
1507 \\
1036\end{array}$ \\
\hline $\begin{array}{l}\text { Female } \\
\text { Acute } \\
\text { Asthma/wheezy bronchitis } \\
\text { Allergies } \\
\text { Chronic } \\
\text { Psychosocial } \\
\text { Psychosomatic } \\
\text { None }\end{array}$ & $\begin{array}{l}1 \cdot 223 \\
1.217 \\
1.226 \\
1.215 \\
1.209 \\
1.218 \\
1.219\end{array}$ & $\begin{array}{l}0.061 \\
0.062 \\
0.061 \\
0.068 \\
0.064 \\
0.060 \\
0.059\end{array}$ & $\begin{array}{r}2934 \\
1041 \\
758 \\
878 \\
785 \\
1925 \\
1444\end{array}$ & $\begin{array}{l}1.452 \\
1.445 \\
1.454 \\
1.445 \\
1.433 \\
1.448 \\
1.447\end{array}$ & $\begin{array}{l}0.075 \\
0.078 \\
0.078 \\
0.084 \\
0.078 \\
0.076 \\
0.075\end{array}$ & $\begin{array}{r}2486 \\
870 \\
661 \\
721 \\
661 \\
1652 \\
1233\end{array}$ & $\begin{array}{l}1.611 \\
1.606 \\
1.615 \\
1.608 \\
1.603 \\
1.608 \\
1.609\end{array}$ & $\begin{array}{l}0.063 \\
0.064 \\
0.064 \\
0.068 \\
0.066 \\
0.062 \\
0.060\end{array}$ & $\begin{array}{r}2095 \\
759 \\
542 \\
615 \\
568 \\
1399 \\
1049\end{array}$ & $\begin{array}{l}1.625 \\
1.622 \\
1.630 \\
1.620 \\
1.615 \\
1.622 \\
1.621\end{array}$ & $\begin{array}{l}0.068 \\
0.070 \\
0.067 \\
0.072 \\
0.069 \\
0.066 \\
0.066\end{array}$ & $\begin{array}{r}2412 \\
834 \\
630 \\
695 \\
625 \\
1587 \\
1227\end{array}$ \\
\hline
\end{tabular}

^Illness groups are not mutually exclusive. 
Table 2 Height deficits (cm) at different ages for selected childhood morbidity groups $\dagger$ (both sexes combined)

\begin{tabular}{|c|c|c|c|c|c|c|c|c|c|c|c|c|}
\hline & \multicolumn{12}{|c|}{ Age of follow up } \\
\hline & \multicolumn{3}{|l|}{7 Years } & \multicolumn{3}{|c|}{11 Years } & \multicolumn{3}{|c|}{16 Years } & \multicolumn{3}{|c|}{23 Years } \\
\hline & (No) & Unadjusted $^{\mathrm{a}}$ & Adjusted $^{\mathrm{b}}$ & (No) & Unadjusted $^{\mathrm{a}}$ & Adjusted $^{\mathrm{b}}$ & (No) & Unadjusted $^{\mathrm{a}}$ & Adjusted $^{\mathrm{b}}$ & (No) & Unadjusted $^{\mathrm{a}}$ & Adjusted $^{\mathrm{b}}$ \\
\hline $\begin{array}{l}\text { Chronic } \\
\text { Psychosocial } \\
\text { Asthma/wheezy bronchitis }\end{array}$ & $\begin{array}{l}(1951) \\
(1853) \\
(2447)\end{array}$ & $\begin{array}{l}0.44^{\star} \\
0 \cdot 77^{\star \star} \\
0.06\end{array}$ & $\begin{array}{l}0 \cdot 22 \\
0.45^{\star \star} \\
0.07\end{array}$ & $\begin{array}{l}(1602) \\
(1530) \\
(2044)\end{array}$ & $\begin{array}{l}0 \cdot 47^{\star} \\
1 \cdot 14^{\star \star} \\
0 \cdot 04\end{array}$ & $\begin{array}{l}0 \cdot 29 \\
0.66^{\star \star} \\
0.04\end{array}$ & $\begin{array}{l}(1346) \\
(1311) \\
(1718)\end{array}$ & $\begin{array}{l}0 \cdot 40 \\
0.76^{\star \star} \\
0 \cdot 13\end{array}$ & $\begin{array}{l}0.27 \\
0 \cdot 43^{\star} \\
0 \cdot 08\end{array}$ & $\begin{array}{l}(1494) \\
(1409) \\
(1910)\end{array}$ & $\begin{array}{l}0.45^{\star} \\
0.54^{\star} \\
0.05\end{array}$ & $\begin{array}{l}0 \cdot 28 \\
0 \cdot 32 \\
0 \cdot 02\end{array}$ \\
\hline
\end{tabular}

${ }^{\mathrm{a} C}$ Corrected for date of height measure and sex.

${ }^{6}$ Corrected for date of height measure, sex, social class at birth, maternal height, birth weight, and parity. (The samples in the adjusted analyses are slightly smaller than those shown.) Interactions were not significant; all analyses are main effects only.

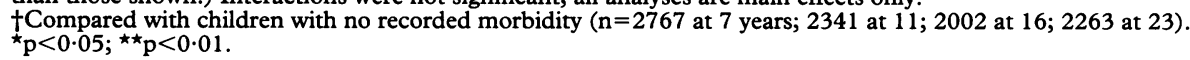

years. Children with no reported illness provide a comparison group. Although no statistical tests were performed at this stage, children with chronic and psychosocial illnesses appeared to be shorter on average than others, an effect that persisted for each sex and age, including adult height at age 23. Asthmatic children also appeared to be shorter but not consistently so across each sex and age. Morbidity categories are not mutually exclusive, except between children with no reported illness by 7 years and other groups. Mutually exclusive groups were obtained by creating an additional category of more than one condition. Each of the seven morbidity groups was then compared with the no illness group. However, results for children with more than one condition were difficult to interpret because the direction of effect differed by morbidity group (table 1).

Significant height differences were found for two groups: chronic and psychosocial illness, although after adjustment for multiple comparisons using the Bonferron method, ${ }^{23}$ significant differences remained only for psychosocial problems. None the less, further analyses are presented for both the chronic and psychosocial groups. Also included are more detailed analyses for asthma, since other studies suggest an effect of this condition on growth.

Table 2 shows significant height deficits $(p<0.05)$ at age 7 for the chronic and psychosocial groups. Interactions between social class, height, and morbidity group, for example, were not significant; therefore table 2 is limited to main effects. Children with a chronic illness by age 7 are almost $0.5 \mathrm{~cm}$ shorter, on average, than children with no recorded illnesses. This difference is statistically significant $(p<0.05)$ and is maintained at each age, except 16 years. After adjustment for other height related factors (see
Methods), children with chronic conditions are no longer significantly shorter (table 2).

Analyses of chronic conditions were extended using three subgroups for each sex separately (table 3): each subgroup is shorter (compared with those with no illness at age 7) except among females at age 16 for physical and mental handicap, and at age 23 for chronic medical conditions. When mutually exclusive subgroups of chronic conditions were used, $9.6 \%$ of those with a chronic condition (188 out of 1951 at age 7) were identified as having more than one condition. These children were significantly shorter throughout early life: by $1.9 \mathrm{~cm}(1.57 \mathrm{~cm}$ after adjustment) at age 7 , and by $2 \mathrm{~cm}(1.7 \mathrm{~cm}$ after adjustment) at age 23. The remainder with one chronic condition were not significantly shorter after adjustment for other height related factors.

Compared to those with no recorded illness by age 7 , children categorised as having psychosocial problems were significantly shorter by $0.77 \mathrm{~cm}$ at this age (table 2). Although the magnitude of the height deficit varied, the shorter stature of children with psychosocial problems persisted through to adulthood. After adjustment for other height related factors a significant difference remained at each age, except 23 years, suggesting that catch up growth had occurred.

Given the association between height and psychosocial illness, analyses were extended to examine whether the majority included in this group, namely children with enuresis, were more adversely affected if their problem persisted over several years. From information on enuresis obtained at ages 7 and $11,8.9 \%$ of the cohort were identified as enuretic by age 7 but not thereafter; $4.6 \%$ were enuretic at age 11 . Table 4 shows that height deficits were most pronounced for children with persistent enuresis and for those apparently acquiring an enuresis problem between ages 7 and 11. For

Table 3 Mean height (metres) at different ages for children with chronic illness at age 7

\begin{tabular}{|c|c|c|c|c|c|c|c|c|c|c|c|c|}
\hline \multirow[b]{3}{*}{ Chronic illness at age 7} & \multicolumn{12}{|c|}{ Age at follow up } \\
\hline & \multicolumn{3}{|c|}{7 Years } & \multicolumn{3}{|c|}{11 Years } & \multicolumn{3}{|c|}{16 Years } & \multicolumn{3}{|c|}{23 Years } \\
\hline & Mean & $S D$ & No & Mean & $S D$ & No & Mean & $S D$ & No & Mean & $S D$ & $\mathrm{No}$ \\
\hline $\begin{array}{l}\text { Boys } \\
\text { Chronic medical } \\
\text { Physical/mental handicap } \\
\text { Sensory impairment }\end{array}$ & $\begin{array}{l}1 \cdot 220 \\
1 \cdot 222 \\
1 \cdot 214\end{array}$ & $\begin{array}{l}0.063 \\
0.065 \\
0.068\end{array}$ & $\begin{array}{l}277 \\
647 \\
283\end{array}$ & $\begin{array}{l}1.429 \\
1.436 \\
1.426\end{array}$ & $\begin{array}{l}0.079 \\
0.078 \\
0.078\end{array}$ & $\begin{array}{l}226 \\
525 \\
228\end{array}$ & $\begin{array}{l}1.693 \\
1.695 \\
1.685\end{array}$ & $\begin{array}{l}0.098 \\
0.095 \\
0.095\end{array}$ & $\begin{array}{l}176 \\
444 \\
198\end{array}$ & $\begin{array}{l}1 \cdot 769 \\
1.767 \\
1.762\end{array}$ & $\begin{array}{l}0.074 \\
0.078 \\
0.083\end{array}$ & $\begin{array}{l}198 \\
489 \\
198\end{array}$ \\
\hline $\begin{array}{l}\text { Girls } \\
\text { Chronic medical } \\
\text { Physical/mental handicap } \\
\text { Sensory impairment }\end{array}$ & $\begin{array}{l}1 \cdot 213 \\
1 \cdot 216 \\
1 \cdot 204\end{array}$ & $\begin{array}{l}0.069 \\
0.070 \\
0.068\end{array}$ & $\begin{array}{l}266 \\
500 \\
189\end{array}$ & $\begin{array}{l}1.445 \\
1.442 \\
1.435\end{array}$ & $\begin{array}{l}0.089 \\
0.088 \\
0.089\end{array}$ & $\begin{array}{l}225 \\
405 \\
155\end{array}$ & $\begin{array}{l}1.608 \\
1.610 \\
1.600\end{array}$ & $\begin{array}{l}0.066 \\
0.072 \\
0.068\end{array}$ & $\begin{array}{l}184 \\
350 \\
127\end{array}$ & $\begin{array}{l}1.621 \\
1.617 \\
1.616\end{array}$ & $\begin{array}{l}0.070 \\
0.076 \\
0.077\end{array}$ & $\begin{array}{l}217 \\
383 \\
149\end{array}$ \\
\hline
\end{tabular}


Table 4 Height deficits (cm) for enuretic children† (both sexes combined)

\begin{tabular}{|c|c|c|c|c|c|c|c|c|c|}
\hline \multirow[b]{3}{*}{ Enuresis groups } & \multicolumn{9}{|c|}{ Age at follow up } \\
\hline & \multicolumn{3}{|c|}{11 Years } & \multicolumn{3}{|c|}{16 Years } & \multicolumn{3}{|c|}{23 Years } \\
\hline & (No) & Unadjusted $^{\mathrm{a}}$ & Adjusted $^{\mathrm{b}}$ & (No) & Unadjusted $^{\mathbf{a}}$ & Adjusted $^{\mathrm{b}}$ & (No) & Unadjusted $^{\mathrm{a}}$ & Adjusted $^{\mathrm{b}}$ \\
\hline $\begin{array}{l}\text { Age } 7 \text { only } \\
\text { Age } 7 \text { and } 11 \text { or } 11 \text { only }\end{array}$ & $\begin{array}{l}(986) \\
(513)\end{array}$ & $\begin{array}{l}1.20 \\
2.05 \\
\star \star\end{array}$ & $\begin{array}{l}0.63 \\
1.53 \\
\star \star\end{array}$ & $\begin{array}{l}(747) \\
(398)\end{array}$ & $\begin{array}{l}0.78 \\
1 \cdot 26 \\
\star \star\end{array}$ & $\begin{array}{l}0.33 \\
0.94 \\
\star \star\end{array}$ & $\begin{array}{l}(809) \\
(408)\end{array}$ & $\begin{array}{l}0 \cdot 18 \\
1 \cdot 26 \\
\star \star\end{array}$ & $\begin{array}{c}+0 \cdot 14^{c} \\
1 \cdot 11 \\
\star \star\end{array}$ \\
\hline
\end{tabular}

aCorrected for date of height measure and sex.

bCorrected for date of height measure, sex, social class at birth, maternal height, birth weight, and parity. (The samples in the adjusted analyses are slightly smaller than those shown.)

cHeight excess.

†Compared with those with no enuresis problems ( $n=9559$ at 11 years; 7345 at $16 ; 8123$ at 23 ).

Interactions: at age 11 there was a significant interaction $(p<0.05)$ between sex and enuresis group (the effect of enuresis on height was in the same direction for both sexes but the effect appeared greater among girls). No further significant interactions were found. was in the
$\star \star \mathrm{p}<0.01$.

example, the unadjusted 11 year height deficit of children enuretic at age 11 is $2.05 \mathrm{~cm}$ compared with children with no problems, whereas it is $1.20 \mathrm{~cm}$ for those with problems by age 7 but not thereafter. Height differences attenuate after adjustment for other factors and with age, but remain significant at age 23. Children with enuresis at age 11 were more than $1 \mathrm{~cm}$ shorter in adulthood, even allowing for other height related factors. These results were not explained by co-association of enuresis and chronic illness, since similar results were obtained when analyses were repeated with the chronic illness group omitted.

As mentioned above further analyses were undertaken for asthma/wheezy bronchitis, although no significant height deficits were apparent (table 2). In order to account for disease duration, six groups were constructed to represent AWB from ages 7 to 16 (see Methods for definition). A significant effect on mean height at ages 16 and 23 was found (table 5). However, category 2 (AWB before age 7 , and subsequently at ages 11 and 16) comprised a disproportionate number of cases from non-manual social classes. The height difference in this category appeared to reflect this class bias, because after adjustment for social class and maternal height, there was no longer a significant effect. Disease severity was also examined, but analyses were limited because of small numbers: for example, severe cases $(n=70)$ identified at age 11 were $1 \mathrm{~cm}$ shorter than non-severe cases $(n=1175)$.

\section{Discussion}

Evidence of the impact of common medical conditions on childhood growth is fragmentary

Table 5 Height deficits ${ }^{\dagger}(\mathrm{cm})$ for children with asthma/wheezy bronchitis (both sexes combined) compared with 5506 non-asthmatics

\begin{tabular}{|c|c|c|c|c|c|}
\hline \multirow[b]{3}{*}{$A W B$ categories } & & \multicolumn{4}{|c|}{ Age at follow up } \\
\hline & & \multicolumn{2}{|l|}{16 Years } & \multicolumn{2}{|l|}{23 Years } \\
\hline & & Unadjusted $^{\mathrm{a}}$ & Adjusted $^{\mathrm{b}}$ & Unadjusted $^{\mathrm{a}}$ & Adjusted $^{\mathrm{b}}$ \\
\hline $\begin{array}{l}\text { Before age } 7 \text { only } \\
\text { At ages } 7,11 \text {, and } 16 \\
\text { At either } 11 \text { or } 16 \\
\text { At } 11 \text { and } 16 \\
\text { At } 7 \text { and either } 11 \text { or } 16\end{array}$ & $\begin{array}{l}(838) \\
(427) \\
(573) \\
(162) \\
(453)\end{array}$ & $\begin{array}{c}0.57 \\
0.17 \\
0.78 \\
+0.45 \\
0.11 \\
\star\end{array}$ & $\begin{array}{c}0.27 \\
0.01 \\
0.20 \\
0.10 \\
0.24 \\
\text { NS }\end{array}$ & $\begin{array}{r}0.44 \\
+0.48 \\
0.71 \\
+0.07 \\
0.06 \\
\star\end{array}$ & $\begin{array}{r}0.18 \\
+0.40 \\
0.18 \\
0.45 \\
0.29 \\
\text { NS }\end{array}$ \\
\hline
\end{tabular}

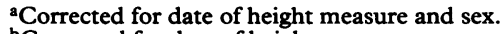

bCorrected for date of height measure, sex, social class at birth, maternal height, birth weight, and parity. (The sample sizes in the adjusted analyses are slightly smaller than those shown.) tExcept where ' + ' indicates an increase. ${ }^{\star} \mathrm{p}<0.05$. and is usually based on small groups from clinic populations from which general conclusions cannot be drawn. Only rarely are longer term associations with adult height investigated. The present study is unique in its comprehensive assessment of the effect of childhood morbidity in a large and nationally representative sample. Early childhood is regarded as especially critical for growth and therefore provides the main focus of inquiry. The approach complements smaller studies of particular diagnostic groups.

\section{PSYCHOSOCIAL PROBLEMS (ENURESIS)}

The psychosocial category was comprised mainly of enuresis. For this category associations with height were particularly notable and, for some, long lasting. Short term effects on height were apparent for enuretic children detected from the 7 year follow up (that is, wetting by day after age 3 or at night after age 5). Shorter stature in enuretic children has been shown previously, among this cohort ${ }^{24}$ and among other children ${ }^{25}$ 26; elsewhere skeletal maturational delay has been observed. ${ }^{27}$ The present investigation suggests that the relationship is partly accounted for by other factors such as maternal height, birth weight, and social class. Nevertheless, almost $9 \%$ of the sample had delayed growth associated with less persistent enuresis, even though they appeared to catch up by early adulthood. Such long term associations have not been shown previously.

It is also notable that the relationship between enuresis at age 11 and height persists through adolescence to adulthood. Fewer children had a problem at age 11 than at age 7 , but even so substantial numbers were affected (about one child in 20). The height deficit of this group diminished between ages 11 and 16 and also with adjustment for other height related factors. None the less, these individuals remained shorter adults, by more than $1 \mathrm{~cm}$ at age 23. This is a substantial deficit which exceeds that associated with manual class origins compared with non-manual $(0.68 \mathrm{~cm}$ after adjustment); or with a second or more order birth compared with a first birth $(0.72$ $\mathrm{cm}$ after adjustment).

Further evidence from the cohort study suggests developmental delay in enuretic children. Doctors assessed stage of puberty as 'immature' more frequently for enuretic 
Table 6 Prevalence (\%) of motor coordination difficulties according to enuresis categories

\begin{tabular}{|c|c|c|c|}
\hline $\begin{array}{l}\text { Teachers' assessment } \\
\text { of coordination }\end{array}$ & $\begin{array}{l}\text { Enuresis } \\
\text { before age } 7\end{array}$ & $\begin{array}{l}\text { Enuresis } \\
\text { at age } 11\end{array}$ & $\begin{array}{l}\text { No enuresis } \\
\text { problem }\end{array}$ \\
\hline $\begin{array}{l}\text { At age 7: } \\
\text { Poor hand control } \\
\text { Squirmy, fidgety } \\
\text { Poor coordination } \\
\text { Clumsy }\end{array}$ & $\begin{array}{l}(1035) \\
6 \cdot 4 \\
9 \cdot 8 \\
4 \cdot 4 \\
2 \cdot 9\end{array}$ & $\begin{array}{c}(540) \\
10 \cdot 2 \\
15 \cdot 4 \\
5 \cdot 2 \\
3.9\end{array}$ & $\begin{array}{l}(10084) \\
3.5 \\
5 \cdot 6 \\
2.0 \\
1.8\end{array}$ \\
\hline \multirow[t]{2}{*}{$\begin{array}{l}\text { At age 11: } \\
\text { Poor hand control } \\
\text { Squirmy, fidgety } \\
\text { Poor physical } \\
\text { coordination }\end{array}$} & $\begin{array}{l}(972) \\
4 \cdot 2 \\
5 \cdot 1\end{array}$ & $\begin{array}{c}(509) \\
6 \cdot 1 \\
8 \cdot 3\end{array}$ & $\begin{array}{l}(9423) \\
2 \cdot 4 \\
3 \cdot 3\end{array}$ \\
\hline & $4 \cdot 0$ & $4 \cdot 6$ & $2 \cdot 2$ \\
\hline
\end{tabular}

^Judged to 'certainly apply' to the child.

children: pubic hair was absent or sparse at age 16 in $13.1 \%$ of boys with enuresis by age 7 , and in $15.1 \%$ with enuresis at age 11 , compared with $11.6 \%$ in other boys; among girls, menstruation started at age 15 or later in $9 \cdot 2 \%$ with enuresis by age 7 , and in $8.3 \%$ with enuresis at age 11 , compared with $6.9 \%$ of other girls. Signs of clinical disorder in enuretic children compared with controls include poorer fine and gross motor perceptual dysfunction. This was shown previously in the 1958 birth cohort ${ }^{24}$ and the data are presented in table 6 . Both enuresis groups, but particularly those with enuresis at age 11 , were more frequently assessed as having poor motor coordination.

It has been argued that there are many causes of enuresis including organic, genetic, developmental, and psychosocial factors, with psychosocial causes predominating for secondary enuresis and biological factors for primary enuresis. ${ }^{28}$ Evidence implicating biological causes of primary enuresis emerged from a birth cohort in which the child's developmental level at 1 and 3 years and a family history of enuresis predicted primary enuresis, while psychosocial factors did not. ${ }^{29}$ This calls into question the inclusion of enuresis as a psychosocial illness in the classification scheme used here.

However, there is also support for psychosocial causes of the enuresis/height association, particularly for those acquiring a problem. Enuretic children have been shown to experience more stressful events such as marital separation, 2530 adverse social circumstances such as family hardship, overcrowded homes, and being in public care. ${ }^{24}$ The stresses that may increase a child's susceptibility to enuresis can affect cortisol levels and thereby affect height. Evidence of an adverse effect of psychological stress on height was documented in Widdowson's classic paper ${ }^{31}$ in which orphanage children subjected to harsh and unsympathetic handling had curtailed growth. Stunting effects of severe emotional disturbance have also been suggested by the extensive literature on failure to thrive. ${ }^{13}$ Conversely, catch up growth may be initiated by psychological intervention. ${ }^{32}$

Primary and secondary enuresis could not be distinguished confidently in the present study, partly because of the possible unreliability of parental reporting of enuresis on successive follow up. However, children who appeared to have acquired an enuresis problem between the ages of 7 and $11(122 / 513)$ resembled others with enuresis at age 11 in having shorter stature at each age through to early adulthood.

Whatever the cause, shorter adult stature has implications for health in later life, possibly including cardiovascular disease, ${ }^{33}{ }^{34}$ tuberculosis, and obstructive lung disease, ${ }^{33}$ mortality from falls and fractures, ${ }^{35}$ and reproductive success in women. ${ }^{36}$ Shorter stature is associated with worse socioeconomic circumstances, a relationship that is reinforced by downward social mobility. ${ }^{6}$ Hence there may be additional consequences for short adults.

Childhood enuresis may be associated with other sequelae in adult life, for example with social functioning, educational achievement, and psychological wellbeing, and with longer term health. This would be important to establish; together with the results shown here, such evidence might justify the development of a child health index (comprising enuresis and other indicators of developmental delay) for population monitoring.

\section{CHRONIC ILLNESS}

It is already well known that several chronic paediatric diseases can impair growth and adult stature. Such conditions include cystic fibrosis, gastrointestinal disease (coeliac and inflammatory bowel disease, the latter comprising Crohn's disease and ulcerative colitis), and congenital heart disease. ${ }^{737}$ These are, in general, likely to be more severe than the majority of conditions classified as chronic in the present study. ${ }^{19}$ Children with chronic illnesses are also more likely to be lost to follow up. Furthermore, by grouping diverse chronic conditions together, the effects on growth of certain severe conditions may be obscured. None the less, the small proportion with the most severe conditions ( $1.4 \%$ with more than one condition) were $2 \mathrm{~cm}$ shorter than their contemporaries. These children did not catch up and they became shorter adults. Furthermore, the growth retarding effect of their conditions did not appear to be explained by growth in utero and other height related factors. Others with chronic illness showed less marked stunting effects which to some extent reflected their lower birth weight, maternal height, parity, and social background. Not surprisingly, therefore, the magnitude of stature deficits appeared to vary with severity as well as with the type of condition.

\section{ASTHMA}

The potentially growth retarding effect of asthma is of particular concern because the prevalence of this important paediatric condition may be increasing. ${ }^{38}$ Much of the evidence on the impact of asthma on growth has been based on highly selected clinic populations, with severe intractable disease. Differences in asthma severity may partly explain discrepant findings in asthma and growth studies. ${ }^{10}$

The present study does not show a growth retarding effect of childhood asthma. In contrast to a previous analysis of the birth 
cohort, ${ }^{39}$ this finding is based on an undifferentiated category of asthma or wheezy bronchitis, since the clinical or pathological grounds for distinguishing between them are poor. ${ }^{22}$ It nevertheless confirms the previously reported lack of an effect of asthma on height in this cohort by age $16 .^{39}$ Furthermore, the results accord with other studies of adult height. 8111240 As Russell ${ }^{10}$ comments, it is notably community based surveys, such as the present one, that commonly fail to show growth retarding effects of asthma. Community studies contain only a small proportion of children with severe asthma, for whom evidence of a growth retarding effect is strongest. Those identified from the birth cohort as having severe asthma appeared to be shorter than their contemporaries, but no significant effect was detected, possibly because of the small number of cases. Persistence of disease was not associated with adolescent and adult stature once allowance was made for other known influences on height. However, these results do not address concerns about the effects of drugs, such as systemic or inhaled corticosteroids, used currently for the treatment of asthma.

\section{JUSTIFICATION FOR HEIGHT AS A CHILD HEALTH INDEX}

These data suggest, for a large British cohort, that most childhood diseases do not affect height, either in the short or the long term. Exceptions are enuresis and some chronic conditions. The height deficit for enuretic children is particularly notable because enuresis is a common paediatric problem. ${ }^{41}$ In contrast, severe chronic illness is rare in childhood and even though it may be increasing through improved survival of children with previously life threatening conditions, ${ }^{14}$ the impact on height in large unselected populations is likely to remain limited.

It has been stated that 'a child's growth rate reflects better than any other single index, his state of health and nutrition and often indeed his psychological situation too'. ${ }^{42}$ The present study suggests that it would be inappropriate to extend this to 'static' height measurements. However, additional longitudinal follow up is required before we can establish the extent to which childhood growth and adult height influence health status in the long term. Further analyses of the 1958 birth cohort will assess the adequacy of height as an indicator of health. Such research is important because there is a need for measures of morbidity which can be used to monitor the nation's health.

While the information in the 1958 British Birth Cohort Study affords a unique opportunity to assess growth influences in a large national sample, inevitably there are shortcomings of such studies. Sample attrition and bias may be a problem, as children with psychosocial problems at age 7 were more likely to be lost to follow up at age $23 .{ }^{19}$ Measurement error of height and childhood illness may also occur, although these errors would have to vary systematically in order to affect the relationships described here. Few individuals grow after age 23; therefore it is unlikely, though possible, that height deficits would not be evident after an extended growing period beyond this age.

\section{CONCLUSIONS}

With the exception of the Harpenden growth study (quoted by Preece ${ }^{43}$ ) knowledge relating to common paediatric conditions and growth derives from reports of severe cases referred to hospital. In a large national birth cohort few childhood conditions appeared to affect height either in the short term or in the long term. Among conditions associated with height, the effect of enuresis was particularly marked and long lasting. Given that this is a common childhood problem, it is striking that the adverse height association receives little attention in published reports. This -contrasts with an extensive debate on the height effects of asthma and its treatment, even though effects are likely to be confined to a small group with severe asthma. Chronic illness in childhood also appears to have a detrimental effect on height, but this is long lasting only for a small group with more severe illness. Notwithstanding these findings, the meaning of height as a health indicator needs further clarification in developed countries.

Chris Power is a scholar of the Canadian Institute for Advanced Research and is grateful to them for personal support.

1 Goldstein $\mathrm{H}$. Factors influencing the height of seven-yearold children. Results from the National Child Development Study (1958 cohort). Hum Biol 1971; 43: 92-111.

2 Rona RJ, Swan AV, Altman DG. Social factors and height of primary schoolchildren in England and Scotland. f Epidemiol Community Health 1978; 32: 147-54.

3 Kuh D, Wadsworth M. Parental height: childhood environment and subsequent adult height in a national birth cohort. Int $\mathcal{F}$ Epidemiol 1989; 18: 663-8.

4 Fogelman $K$, Manor O. Smoking in pregnancy and development into early adulthood. BMF 1988; 297: 1233-6.

5 Gulliford M, Chinn S, Rona RJ. Social environment and height: England and Scotland 1987 and 1988. Arch Dis Child 1991; 66: 235-40.

6 Power C, Manor O, Fox AJ. Health and class: the early years. London: Chapman and Hall, 1991.

7 Preece MA, Law CM, Davies PSW. The growth of children with chronic paediatric disease. Clin Endocrinol Metab with chronic paediat

8 Hauspie R, Susanne C, Alexander F. Maturational delay and temporal growth retardation in asthmatic boys. $\boldsymbol{f}$ Allergy Clin Immunol 1976; 57: 342-51.

$9 \mathrm{McNicol} \mathrm{KN,} \mathrm{Williams} \mathrm{HB.} \mathrm{Spectrum} \mathrm{of} \mathrm{asthma} \mathrm{in} \mathrm{child-}$ ren. I. Clinical and physiological components. $B M F 1973$; iv: 7-11.

10 Russell G. Asthma and growth. Arch Dis Child 1993; 69: 695-8.

11 Balfour-Lynn L. Growth and childhood asthma. Arch Dis Child 1986; 61: 1049-55.

12 Martin AJ, McLennan LA, Landau LI, Phelan PD. The natural history of childhood asthma to adult life. $B M \mathcal{F}$ 1980; 280: $1397-400$.

13 Powell GF, Brasel JA, Blizzard RM. Emotional deprivation and growth retardation simulating idiopathic tion and growth retardation simulating idiopat
hypopituitarism. $N$ Engl $\mathcal{F}$ Med 1967; 276: 1271-8.

hypopituitarism. N Engl f Med 1967; 276: $1271-8$.
14 Woodroffe C, Glickman M, Barker M, Power C. Children, teenagers and health: the key data. Milton Keynes: Open teenagers and health: the

15 Botting $\mathrm{B}$, ed. The health of our children. OPCS, London: HMSO, 1995 (in press)

16 Butler NR, Bonham DG. Perinatal mortality. Edinburgh: Livingstone, 1963.

17 Ferri E. Life at 33: the fifth follow-up of the national child development study. London: National Children's Bureau, 1993.

18 Goldstein $\mathrm{H}$. A study of the response rates of 16-year-olds in the NCDS. In: Fogelman K, ed. Growing up in Great Britain. London: Macmillan, 1983: 9-18.

9 Power C, Peckham C. Childhood morbidity and adulthood ill-health. $\mathcal{f}$ Epidemiol Community Health 1990; 44: 69-74. 
20 Knight I. The heights and weights of young adults in Great Britain. London: HMSO, 1984.

21 Power C, Moynihan C. Social class and changes in weightfor-height between childhood and early adulthood. Int $\mathscr{f}$ Obesity 1988; 12: 445-53.

22 Anderson HR, Bland JM, Patel S, Peckham C. The natural history of asthma in childhood. $\mathcal{F}$ Epidemiol Community history of asthma in chilth $1986 ; 40: 121-9$.

23 Millar RG. Simultaneous statistical inference. Berlin: Springer Verlag, 1980.

24 Essen J, Peckham C. Nocturnal enuresis in childhood. Dev Med Child Neurol 1976; 18: 577-89.

25 Jarvelin MR, Moilanen I, Kangas P, et al. Aetiological and precipitating factors for childhood enuresis. Acta Paediatr Scand 1991; 80: 361-9.

26 Jarvelin MR. Developmental history and neurological findings in enuretic children. Dev Med Child Neurol 1989; 31: 728-36.

27 Mimouni M, Shuper A, Mimouni F, Grunebaum M, Varsano I. Retarded skeletal maturation in children with primary enuresis. Eur 7 Pediatr 1985; 144: 234-5.

28 Kolvin I, Taunch J. A dual theory of nocturnal enuresis. In: Kolvin I, MacKeith RC, Meadow SR, eds. Bladder control and enuresis. Clinics in Developmental Medicine 48/49. and enuresis. Clinics in Developmental Medicine 48/49.

29 Fergusson DM, Horwood LJ, Shannon FT. Factors related to age of attainment of nocturnal bladder control: an 8-year longitudinal study. Pediatrics 1986; 78: 884-90.

30 Douglas JWB. Early disturbing events and later enuresis. In: Kolvin I, MacKeith RC, Meadow SR, eds. Bladder control and enuresis. Clinics in Developmental Medicine 48/49. and enuresis. Clinics in Developmental Medicine 48/49. London:

31 Widdowson EM. Mental contentment and physical growth Lancet 1951; i: 1316-8.
32 Fonagy P, Moran GS. Studies on the efficacy of child psychoanalysis. F Consult Clin Psychol 1990; 58: 684-95.

33 Marmot MG, Shipley MJ, Rose G. Inequalities in death specific explanations of a general pattern. Lancet 1984; i: 1003-6.

34 Waaler HTH. Height, weight and mortality. The Norwegian experience. Acta Med Scand 1984; suppl 679

35 Eddy TP. Deaths from domestic falls and fractures. $\mathrm{Br} \dot{f}$ Prev Soc Med 1972; 26: 173-9.

36 Emanuel I. Maternal health during childhood and later reproductive performance. In: Wisniewski HM, Snider D reproductive performance. In: Wisniewski HM, Snider D, eds. Mental retardation: research, education, and technology transfer. Ann NY Acad Sci 1986:477: 27-39.
37 Poskitt EM. Failure to thrive in congenital heart disease Arch Dis Child 1993; 68: 158-60.

38 Anderson HR. Increase in hospital admissions for childhood asthma: trends in referral, severity and readmissions from 1970 to 1985 in a health region of the United Kingdom. Thorax 1989; 44: 614-9.

39 Kaplan BA, Brush G, Mascie-Taylor CGN. The relationship of childhood asthma and wheezy bronchitis with height, weight and body mass index. Hum Biol 1987; 59: 921-31.

40 Shohat M, Shohat T, Kedem R, Mimouni M, Danon YI Childhood asthma and growth outcome. Arch Dis Child 1987; 62: 63-5.

41 Friman PC, Warzak WJ. Nocturnal enuresis: a prevalent, persistent, yet curable parasomnia. Pediatrician 1990; 17 $38-45$.

42 Eveleth PB, Tanner B. Worldwide variation in human growth Cambridge: Cambridge University Press, 1990.

43 Preece MA. Growth measurement as indicators of health status. In: Still E, ed. The health and development of children. Eugenics Society, London: Natterton Books, 1986 